01.1;03.4;01.3

\title{
Пределы горения вспененной эмульсии с высоким содержанием воды
}

\author{
(ㄱ И.С. Яковенко ${ }^{1}$, А.Д. Киверин ${ }^{1}$, А.М. Коршунов ${ }^{2}$, Б.В. Кичатов ${ }^{1,2}$ \\ ${ }^{1}$ Объединенный институт высоких температур РАН, Москва, Россия \\ ${ }^{2}$ Физический институт им. П.Н. Лебедева РАН, Москва, Россия \\ E-mail: yakovenko.ivan@bk.ru
}

Поступило в Редакцию 6 августа 2019г.

В окончательной редакции 12 сентября 2019г.

Принято к публикации 17 сентября 2019г.

\begin{abstract}
Рассматривается перспективный новый подход к сжиганию водонасыщенных углеводородов в форме вспененных эмульсий, устойчивое горение которых в ряде случаев поддерживается при содержании воды более $90 \%$ по массе. На основе расчетно-теоретического анализа продемонстрирован базовый физический механизм, определяющий столь широкие пределы горения и заключающийся в естественном пространственном разделении зоны горения и зоны испарения воды. При этом горючая пена в процессе горения преимущественно распадается на эмульсионные капли. Нестационарные режимы горения определяются структурой пены. Полученные данные определяют область применимости концепции сжигания водонасыщенных углеводородов.
\end{abstract}

Ключевые слова: горючие вспененные эмульсии, водонасыщенное углеводородное топливо, механизмы распространения пламени, численное моделирование.

DOI: 10.21883/PJTF.2019.24.48798.18010

\begin{abstract}
Эмульсионные топлива на основе углеводородов с добавлением воды представляют интерес с точки зрения широкого класса приложений, включая традиционную энергетику [1] и биоэнергетику [2]. Актуальными являются задачи утилизации водонасыщенных углеводородов, в том числе задача очистки акваторий от нефтяных разливов [3]. Добавление воды к углеводородному топливу в форме распыла или в составе эмульсионного топлива может использоваться с целью снижения температуры продуктов горения и сокращения эмиссии вредных выбросов, в частности окислов азота [4] и наночастиц сажи [5]. Однако следует отметить, что горение водонасыщенных топлив неустойчиво и, как правило, характеризуется весьма узкими пределами горения [6]. Тем не менее если обеспечить определенные условия подготовки топлива, то пределы устойчивого горения могут быть существенно расширены. Так, в недавних работах авторов [7] было продемонстрировано, что горение эмульсий углеводород-вода, вспененных кислородом, поддерживается даже при высоком содержании воды ( 90\% по массе и выше). Таким образом, горючая система на основе вспененной эмульсии обладает уникальными свойствами и представляет собой новый перспективный класс топлива. Для обоснования возможности практического применения вспененных эмульсий необходимо точно определить пределы их горения в зависимости от состава и условий сжигания. Для этого в свою очередь необходимо выявить физические механизмы, обеспечивающие горение вспененной эмульсии с высоким содержанием воды. В рамках настоящей работы на основе анализа полученных ранее экспериментальных данных и специально проведенного расчетно-
\end{abstract}

теоретического анализа сформулирован базовый механизм горения вспененной эмульсии, определены пределы горения и выявлены особенности развития горения, связанные с неоднородной структурой пены.

Вспененная эмульсия представляет собой двухфазную систему, состоящую из микропузырей кислорода, разделенных пленками жидкости, в состав которой входит эмульсия углеводород-вода. Подробно с технологиями приготовления таких пен можно ознакомиться в работе [7]. Как показывает практика [7], горючими являются пены, в состав которых входят легкие летучие углеводороды с поверхностным натяжением на межфазной границе углеводород-вода, которое обеспечивает выход углеводородных капель на свободную поверхность воды [8]. Ввиду малого содержания углеводородов в пене жидкая фаза пены, как правило, представляет собой прямую эмульсию или эмульсию типа масло в воде.

С учетом указанных выше особенностей структуры пены предложим следующий механизм горения пены (рис. $1, a)$. Под действием теплового потока от фронта пламени пена (область I на рис. 1,a) разрушается с формированием капельной взвеси в атмосфере кислорода (область II на рис. 1,a). При этом возможны два принципиальных сценария: 1) пена распадается на относительно крупные капли воды и более мелкие капли углеводородного топлива; 2) пена распадается на эмульсионные капли. Важно отметить, что во втором случае ввиду выполнения условия выхода углеводорода на свободную поверхность воды эмульсионная капля представляет собой водяное ядро, ограниченное углеводородной оболочкой (рис. $1, b$ ). При достаточном содержании углеводорода в эмульсии вся поверхность 


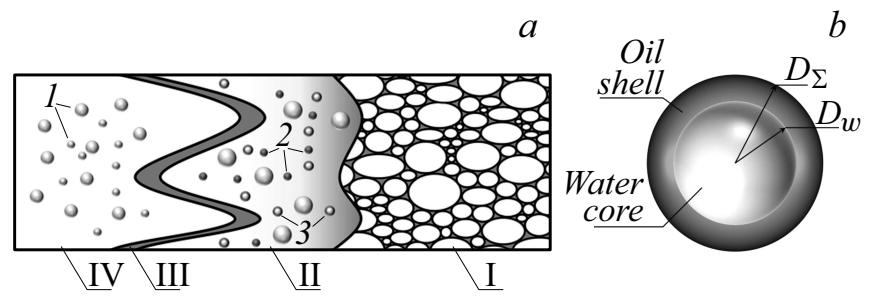

Рис. 1. $a-$ механизм распространения фронта горения во вспененной эмульсии. I - невозмущенная пена, II газокапельная среда, сформированная в результате распада пены, III - фронт горения, IV - область продуктов горения. 1 - капли воды, 2 - капли гептана, 3 - эмульсионные капли. $b$ - структура эмульсионной капли. $D_{w}$ - диаметр водяного ядра, $D_{\Sigma}-$ диаметр капли.

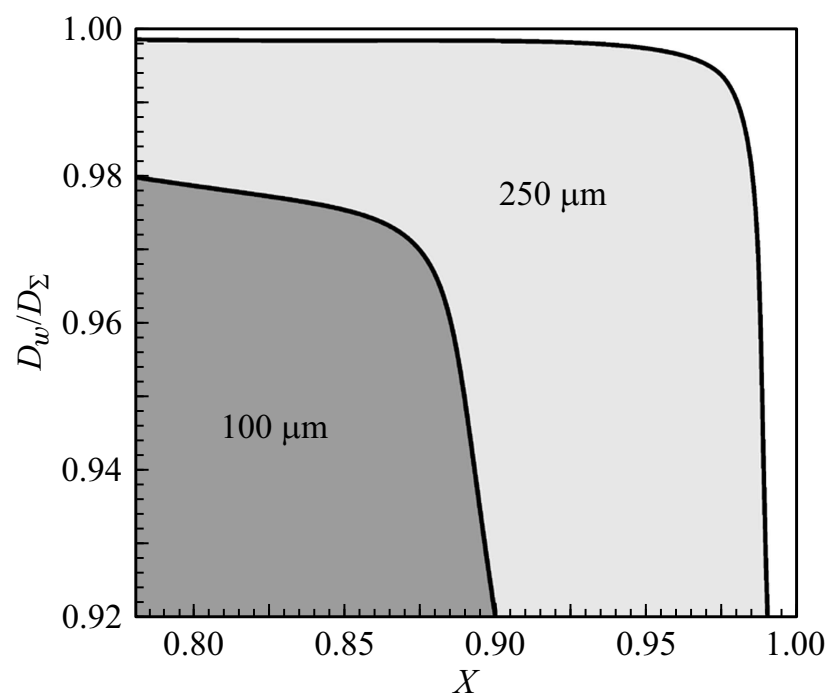

Рис. 2. Пределы самоподдерживаемого горения газокапельной среды, состоящей из эмульсионных капель, в зависимости от массовой доли жидкости $X$ и отношения диаметра водяного ядра $D_{w}$ к полному диаметру капли $D_{\Sigma}$ для эмульсионных капель с полным диаметром $D_{\Sigma}=250$ и $100 \mu \mathrm{m}$.

капли покрыта углеводородом; следовательно, в отличие от альтернативного сценария 1 во фронте горения испаряется исключительно углеводород, тогда как вода испаряется за фронтом пламени (область III на рис. 1, $a$ ) в области продуктов горения (область IV на рис. 1,a). Таким образом, реализуется естественное разделение в пространстве зон горения и испарения воды. Аналогичное предположение было сделано ранее в [7] в отношении сценария с распадом пены на крупные капли воды и мелкие капли углеводорода. К сожалению, оптическая экспериментальная диагностика не позволяет детально исследовать механизм распада в непрозрачной среде. С целью выявления конкретного базового механизма распада пены и, как следствие, механизма поддержания горения в пене в настоящей работе проведено численное моделирование распространения пламени в газокапельных взвесях, моделирующих продукт распада пены. Рассмотрены оба упомянутых выше сценария и определены пределы их реализации. В реальной системе данные сценарии распада пены реализуются совместно, однако, как показывает анализ, приведенный далее, горение пены с высоким содержанием воды возможно только при преобладании механизма распада пены на эмульсионные капли.

Примем следующую постановку задачи, которая отражает два предложенных механизма распада пены. Будем рассматривать распространение плоского пламени в одномерной области, заполненной кислородом с взвешенными эмульсионными каплями или двумя семействами мелких углеводородных и крупных водяных капель. Размеры капель определялись согласно экспериментальным данным по размерам углеводородных капель в эмульсии и размеру каналов Плато в пене [7]. В качестве варьируемых параметров выбирались содержание углеводорода (гептана) в эмульсии, содержание жидкости в пене и степень неоднородности пространственного распределения жидкости. Динамика газокапельной среды рассчитывалась в континуальном приближении с использованием классической двухтемпературной двухскоростной модели [9]. Ввиду малого размера капель и относительно небольших их объемных концентраций испарение капель предполагалось ограниченным процессами теплопереноса. При этом подразумевалось, что процессы горения протекают в газовой фазе [10]. Кинетика горения гептанкислородной смеси описывалась глобальным одноступенчатым механизмом на основе механизма, предложенного для описания окисления сложных углеводородов B [11].

Рассмотрим горение газокапельной среды, состоящей из эмульсионных капель в атмосфере кислорода. Исходя из экспериментальных данных размеры каналов Плато в горючих вспененных эмульсиях составляют $\sim 250 \mu \mathrm{m}$. Процесс распада пены представляет собой разрыв тонких пленок, соединяющих каналы Плато в пене, в связи с этим размер капель жидкости, формируемых при распаде пены, соответствует размеру каналов Плато. Исходя из этого будем считать, что при распаде пены формируются эмульсионные капли диаметром $250 \mu \mathrm{m}$. На рис. 2 закрашенными областями показаны пределы горения газокапельной среды при изменении массовой доли жидкости $X$ и содержания гептана, которое определяется отношением диаметра водяного ядра $D_{w}$ к общему диаметру эмульсионной капли $D_{\Sigma}$ (рис. $\left.1, b\right)$. Так, устойчивое горение газокапельной среды из эмульсионных капель с диаметром $250 \mu$ о оказывается возможным в диапазоне параметров $X<0.975$ и $D_{w} / D_{\Sigma} \leqslant 0.997$ (отношение массы гептана $m_{h}$ к массе воды $m_{w}$ должно быть выше чем 0.006). Для сравнения расчеты в рамках данной модели показали, что при уменьшении размеров эмульсионных капель пределы горения сужаются. Так, в газокапельной среде с эмульсионными каплями диаметром $100 \mu \mathrm{m}$ устойчивое горение возможно только при $X<0.875$ и $D_{w} / D_{\Sigma} \leqslant 0.97\left(m_{h} / m_{w}>0.065\right)$. 

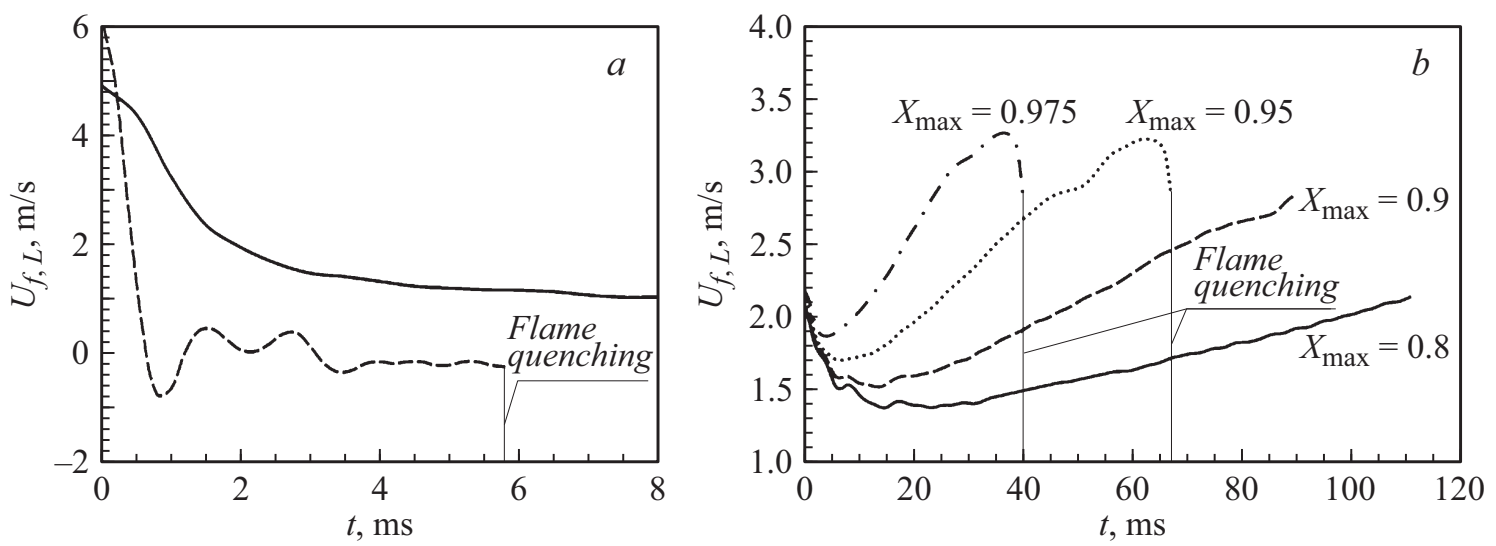

Рис. 3. $a$ - динамика распространения фронта горения в газокапельной среде, состоящей из эмульсионных капель диаметром $250 \mu \mathrm{m}$ (сплошная линия), и в газокапельной среде, состоящей из отдельных капель воды диаметром $249.5 \mu \mathrm{m}$ и капель гептана диаметром $52 \mu \mathrm{m}$ (штриховая линия). Отношение масс гептана и воды в обоих случаях одинаково и составляет величину 0.006 . Массовая доля жидкости $X=0.8 . b$ - динамика распространения фронта горения в неоднородной газокапельной среде, состоящей из двух сортов эмульсионных капель с диаметрами 250 и $100 \mu \mathrm{m}$. Степень неоднородности характеризуется минимальной массовой долей жидкости $X_{\min }=0.8$ у верхней границы вспененной эмульсии и различной максимальной массовой долей $X_{\max }$ у нижней границы вспененной эмульсии (указана около кривых). Тонкими вертикальными линиями на обеих частях обозначен момент времени, в который происходит затухание пламени.

Возможность горения газокапельной среды с высоким содержанием воды определяется последовательным характером испарения эмульсионных капель. На начальной стадии испаряется углеводород, сгорающий во фронте пламени. На этом этапе горение эмульсионных капель не отличается от горения капель углеводорода. Пределы горения в данном случае определяются балансом между потерями тепла на испарение и выделением энергии в ходе химических реакций. При этом в случае достаточно крупных капель и избытка углеводорода в эмульсии испарение водяного ядра реализуется на значительном расстоянии за фронтом пламени в области продуктов горения и не оказывает влияния непосредственно на зону реакции. При уменьшении размеров капель или при уменьшении количества углеводорода в эмульсии испарение углеводородной оболочки происходит быстpeе. В результате водяное ядро начинает испаряться непосредственно в предпламенной зоне (область II на рис. $1, a)$. При этом происходит разбавление сформировавшейся горючей смеси и имеют место дополнительные потери тепла на испарение воды, что в совокупности оказывает ингибирующий эффект на процесс распространения пламени. Указанные процессы определяют сужение пределов горения при уменьшении размеров капель и при снижении массовой доли гептана в эмульсии.

Анализ расчетов горения капель гептана в присутствии капель воды показывает существенное сужение пределов горения по сравнению с рассмотренным случаем горения эмульсионных капель. Согласно экспериментальным данным [7], капли гептана в горючей вспененной эмульсии имеют диаметр порядка $50 \mu \mathrm{m}$. Рассмотрим вариант распада пены на отдельные капли воды диаметром $249.5 \mu \mathrm{m}$ и капли гептана диаметром $52 \mu \mathrm{m}$, что соответствует постановке задачи с эмуль- сионными каплями диаметром $250 \mu \mathrm{m}$ и отношением массы гептана к массе воды, равным 0.006. На рис. 3, $a$ представлена зависимость скорости волны реакции при распространении пламени в газокапельной среде с массовой долей жидкости, состоящей из эмульсионных капель или двух типов капель воды и гептана, $X=0.8$. В случае эмульсионных капель наблюдается устойчивое горение газокапельной среды. После короткого периода нестационарного распространения пламени скорость горения релаксирует к постоянному значению (сплошная линия на рис. 3,a). В случае горения мелких капель гептана в присутствии крупных капель воды устойчивого горения при параметрах, соответствующих экспериментальным, не наблюдается. После непродолжительного колебательного процесса горение затухает (штриховая линия на рис. 3,a). Таким образом, естественно предположить, что базовым механизмом распространения горения во вспененных эмульсиях является распад пены на эмульсионные капли, что обеспечивает достаточно широкие пределы поддержания устойчивого горения пены.

Важно отметить, что структура вспененной эмульсии характеризуется высокой пространственной неоднородностью, которая в первую очередь определяется дренажем жидкости и усадкой пены под действием силы тяжести. В результате массовая доля жидкости в нижних слоях пены оказывается выше, чем в верхних слоях. Кроме того, размеры пузырей в нижних слоях пены становятся меньше, чем в верхних, так же как и размеры каналов Плато. Таким образом, при распаде пены в верхних слоях формируются капли большего размера, чем в нижних слоях. Для анализа влияния неоднородного распределения жидкости на распространение горения во вспененной эмульсии были проведены расчеты горения 
газокапельной среды, состоящей из двух сортов эмульсионных капель диаметром 250 и $100 \mu \mathrm{m}$ (отношение массы гептана к массе воды было фиксированным и выбиралось равным $\left.m_{h} / m_{w}=0.166\right)$. Массовая доля крупных капель диаметром $250 \mu \mathrm{m}$ экспоненциально уменьшалась с расстоянием, в то время как массовая доля мелких капель диаметром $100 \mu \mathrm{m}$ экспоненциально увеличивалась. Суммарная массовая доля жидкости при этом увеличивалась с расстоянием от минимальной величины $X_{\min }=0.8$ до максимальной величины $X_{\max }$. Как показывают результаты расчетов (рис. $3, b$ ), неоднородность распределения жидкости может быть причиной формирования нестационарных режимов горения. Так, во всех рассмотренных случаях наблюдается ускорение волны горения при переходе от областей с большим содержанием крупных капель к областям с большим содержанием мелких капель. Распространение пламени в газокапельной среде лимитировано скоростью испарения капель, так как именно испарение определяет формирование горючей смеси. Благодаря большей интенсивности испарения мелких капель по сравнению с интенсивностью испарения крупных капель в газокапельной среде с мелкими эмульсионными каплями формирование горючей смеси происходит быстрее, чем в газокапельной среде с крупными каплями. Именно этим процессом обусловлено ускорение пламени. Однако, как было показано выше, пределы горения в газокапельной среде с эмульсионными каплями диаметром $100 \mu \mathrm{m}$ значительно у́же, чем в среде с эмульсионными каплями диаметром $250 \mu \mathrm{m}$. Этим определяется погасание пламени для градиентов с максимальной массовой долей жидкости $X_{\max }=0.95$ и 0.975 (пунктирная и штрихпунктирная линии на рис. $3, b$ соответственно).

В заключение сформулируем следующие основные результаты работы.

1. Предложена новая горючая система на основе вспененной эмульсии с большим содержанием воды. Продемонстрировано, что базовым механизмом, определяющим самоподдерживаемое горение такой системы, является естественное пространственное разделение зоны горения и зоны испарения воды. При этом показано, что горючая пена преимущественно распадается на эмульсионные капли.

2. На основе численного анализа показано, что пространственная структура пены может определять особенности развития волны горения, включая установление нестационарных режимов распространения пламени, что следует расценивать как дополнительный фактор, определяющий устойчивое горение вспененной эмульсии с большим содержанием воды.

3. Сформулированные физические механизмы в дополнение к полученной ранее эмпирической информации позволяют определить пределы применимости концепции вспененной эмульсии в отношении выбора состава топлива и разработки конкретной технической реализации ее приготовления и сжигания.

\section{Финансирование работы}

Исследование выполнено за счет гранта Российского научного фонда 17-19-01392.

\section{Конфликт интересов}

Авторы заявляют, что у них нет конфликта интересов.

\section{Список литературы}

[1] Huo M., Lin S., Liu H., Lee C.F. // Fuel. 2014. V. 123. P. 218 229. DOI: $10.1016 /$ j.fuel.2013.12.035

[2] Kurgankina M.A., Nyashina G.S., Strizhak P.A. // Appl. Therm. Eng. 2019. V. 147. P. 998-1008. DOI: $10.1016 /$ j.applthermaleng.2018.10.133

[3] Dave D., Ghaly A.E. // Am. J. Environ. Sci. 2011. V. 7. P. 423 440. DOI: 10.3844 /ajessp.2011.423.440

[4] Attia A.M.A., Kulchitskiy A.R. // Fuel. 2014. V. 116. P. 703708. DOI: $10.1016 /$ j.fuel.2013.08.057

[5] Richard J., Garo J.P., Souil J.M., Vantelon J.P., Knorre V.G. // Fire Safety J. 2003. V. 38. P. 569-587. DOI: $10.1016 / \mathrm{S} 0379-7112(03) 00012-2$

[6] Glassman I., Yetter R.A., Glumac N.G. Combustion. London: Academic Press, 2014. 774 p.

[7] Kichatov B., Korshunov A., Kiverin A. // Proc. Combust. Inst. 2019. V. 37. P. 3417-3424. DOI: 10.1016/j.proci.2018.08.007

[8] Denkov N.D. // Langmuir. 2004. V. 20. P. 9463-9505. DOI: $10.1021 / \mathrm{la} 0496760$

[9] Волков К.Н., Емельянов В.Н. Течения газа с частицами. М.: Физматлит, 2008. $600 \mathrm{c.}$

[10] Aggarwal S.K. // Prog. Energy Combust. Sci. 2014. V. 45. P. 79-107. DOI: 10.1016/j.pecs.2014.05.002

[11] Pope D.N., Gogos G. // Combust. Flame. 2005. V. 142. P. 89106. DOI: 10.1016/j.combustflame.2005.02.010 